\title{
Enhanced Mechanical Property of RMI C/SiC Composites with Optimized Porous Carbon Structure by Heat Treatment
}

Ruru Guo (D2395677823@qq.com )

BUAA: Beihang University https://orcid.org/0000-0002-1018-7038

\section{Zhijian Li}

BUAA: Beihang University

Lu Li

BUAA: Beihang University

\section{Peng Wang}

China Aerospace Science and Industry Corp

Chaoli Ma

BUAA: Beihang University

\section{Research Article}

Keywords: C/SiC composites, Porous carbon structure, Mechanical property, Reactive melt infiltration

Posted Date: November 18th, 2020

DOI: https://doi.org/10.21203/rs.3.rs-106300/v1

License: (c) (1) This work is licensed under a Creative Commons Attribution 4.0 International License. Read Full License 


\section{Abstract}

$\mathrm{C} / \mathrm{SiC}$ composites were fabricated by reactive melt infiltration (RMI) using porous $\mathrm{C} / \mathrm{C}$ preforms as the skeleton, followed by the infiltration of molten silicon. A convenient technique of heat treatment in the range of 1500 to $2400{ }^{\circ} \mathrm{C}$ was applied to modify the porous carbon structure. The effects of heat treatment on the porous $\mathrm{C} / \mathrm{C}$ preforms and the as-synthesized $\mathrm{C} / \mathrm{SiC}$ composites were investigated in detail. The results show that the optimal porous carbon structure could be obtained after heat treatment at $1500{ }^{\circ} \mathrm{C}$. After $1500{ }^{\circ} \mathrm{C}$ heat treatment, the median pore size and porosity of the porous $\mathrm{C} / \mathrm{C}$ preform were $9.3 \mu \mathrm{m}$ and $13.65 \%$ respectively, which were in favor of the subsequent infiltration of molten $\mathrm{Si}$. The $\mathrm{C} / \mathrm{SiC}$ composites with the optimized porous carbon structure showed a dense and uniform morphology without obvious cracks. Their bending strength could be up to $276 \mathrm{MPa}$, which was $28 \%$ higher than that of the $\mathrm{C} / \mathrm{SiC}$ composites with untreated $\mathrm{C} / \mathrm{C}$ preforms. However, with the increasing heat treatment temperature $\left(2400^{\circ} \mathrm{C}\right)$, the bending strength of the as obtained composites began to decrease because of the degradation of in-situ fiber strength. The optimized $\mathrm{C} / \mathrm{SiC}$ composites exhibited a typical pseudoplastic fracture behavior with obvious fiber pull-out. The improved mechanical property could be ascribed to the lower porosity of composites, the higher in-situ strength of fibers and the reduced matrix cracks.

\section{Introduction}

The demand for advanced aeroengines with higher speed leads to the further increase in the gas inlet temperature, which stimulates the development of structural materials with outstanding high-temperature properties [1]. Ceramic matrix composites (CMCs) have been recognized as one of the most promising candidates due to their low density, high specific strength, and the improved high-temperature stability [2]. In the $\mathrm{CMC}$ family, $\mathrm{C} / \mathrm{SiC}$ composites have attracted much attention because of their superior hightemperature strength retention and thermophysical properties [3, 4]. Up to date, several different processing routes have been developed to fabricate $\mathrm{C} / \mathrm{SiC}$ composites and the dominant routes include polymer infiltration and pyrolysis (PIP), chemical vapor infiltration (CVI) and reactive melt infiltration (RMI). Among these preparation routes, RMI is ideal for the industrial production and application owing to the low-cost and efficient densification process $[5,6]$.

In RMI process, porous carbon/carbon $(\mathrm{C} / \mathrm{C})$ preforms are firstly prepared by the pyrolysis of resin mixture, followed by the infiltration and reaction of molten $\mathrm{Si}$ to fabricate the $\mathrm{C} / \mathrm{SiC}$ composites. It is well known that the properties of the as-fabricated $\mathrm{RMI} \mathrm{C/SiC} \mathrm{composites} \mathrm{highly} \mathrm{depend} \mathrm{on} \mathrm{the} \mathrm{porous} \mathrm{carbon}$ structure of the preforms (the pore size, the porosity, the wettability with molten $\mathrm{Si}$, et al.) [7, 8]. Up to now, some effort has been devoted to modify the sizes, amount and distribution of the pores in the porous $\mathrm{C} / \mathrm{C}$ preforms by varying the initial carbonaceous precursor and confirm the optimal pore size and volume fraction. Researchers in Shanghai Institute of Ceramics prepared a resin mixture of furfuryl resin, poreforming agent and solvent as the precursor, and controlled the pore distribution of porous carbon by varying the pore-forming agent [9]. The results of Margiotta et al. indicated that the ideal median pore diameter of porous carbon was around $1 \mu \mathrm{m}$, which was beneficial to the fully infiltration of molten $\mathrm{Si}$ and the formation of dense SiC [10]. Singh et al. investigated the effect of initial pore volume fraction on 
the subsequent infiltration and reaction process, which demonstrated that the pore volume fraction of 0.5 could effectively avoid the chocking-off phenomena and the formation of cracks [11]. Wang et al. found that a simple method of heat treatment could effectively increase the apparent porosity and average pore size of the porous carbon, inferring the potential of heat treatment to modify the porous $\mathrm{C} / \mathrm{C}$ preforms without introducing other impurities [12]. However, it is still necessary to systematically investigate the effects of heat treatment on the porous carbon structure and clarify the correlation between the annealing temperature and the mechanical property of the as-fabricated $\mathrm{RMI} \mathrm{C/SiC} \mathrm{composites,} \mathrm{which} \mathrm{is} \mathrm{important}$ for the performance optimization of RMI C/SiC composites.

In the present work, the porous $\mathrm{C} / \mathrm{C}$ preforms were prepared by infiltrating and pyrolyzing a furfuryl resin mixture and then the porous carbon structure in the preforms was modified by heat treatment at different temperatures $\left(1500^{\circ} \mathrm{C}, 1800^{\circ} \mathrm{C}\right.$ and $2400^{\circ} \mathrm{C}$ ). After molten $\mathrm{Si}$ infiltration, the $\mathrm{C} / \mathrm{SiC}$ composites with different porous carbon structure were prepared. The microstructure of the preforms and composites were investigated systematically. The mechanical properties of $\mathrm{C} / \mathrm{SiC}$ composites were tested and the toughening and strengthening mechanisms of the improved composites were analyzed.

\section{Experimental Procedures}

\subsection{Material and Processing}

The preparation of RMI C/SiC composites consists of four steps, 1) weaving and coating fibers, 2) impregnation and pyrolysis of the resin mixture, 3) heat treatment, 4) melt Si infiltration. A schematic of the sample preparation in this work using the RMI process is shown in Fig. 1.

PAN-based carbon fibers (T700, Toray, Japan) were used as raw materials to fabricate the 2.5D preforms of $\mathrm{C} / \mathrm{SiC}$ composites. The $2.5 \mathrm{D}$ preforms were formed by repeatedly stacking fiber web layers, non-woven layers as $0^{\circ} / 90^{\circ} / 0^{\circ} / 90^{\circ}$ pierced with carbon fiber bundles in $\mathrm{Z}$ direction. At first, for protecting the fibers and improving the mechanical properties of composites, a pyrolytic carbon $(\mathrm{PyC})$ interface with a thickness of $\sim 800 \mathrm{~nm}$ was deposited on the fiber surface by the technique of chemical vapor infiltration (CVI) using propane as precursor at $1000^{\circ} \mathrm{C}$ with a reduced pressure of $5 \mathrm{KPa}$ and the deposition time was about $250 \mathrm{~h}$. After the interface deposition, the 2.5D preforms were impregnated with the furfuryl resin mixture (60 wt.\% furfuryl resin, $20 \mathrm{wt}$ \% glycols, $5 \mathrm{wt} . \%$ paratoluene sulfonic acid) in vacuum followed by curing in a drying oven at $200^{\circ} \mathrm{C}$ for $4 \mathrm{~h}$. Then the preforms were pyrolyzed at $900{ }^{\circ} \mathrm{C}$ for $1 \mathrm{~h}$ in argon atmosphere to obtain the porous $\mathrm{C} / \mathrm{C}$ preforms which were marked as $\mathrm{C}$. In order to modify their porosity and structure, the porous $\mathrm{C} / \mathrm{C}$ preforms were annealed at different temperatures $\left(1500^{\circ} \mathrm{C}\right.$, $1800^{\circ} \mathrm{C}$ and $2400^{\circ} \mathrm{C}$ ) for $1 \mathrm{~h}$ in argon atmosphere, respectively. The porous $\mathrm{C} / \mathrm{C}$ preforms after annealing were denoted by C1500, C1800 and C2400, according to the annealing temperatures. Finally, molten Si was infiltrated into these porous C/C preforms (C0, C1500, C1800 and C2400) and reacted with the pyrolysis carbon at $1700^{\circ} \mathrm{C}$ for $1 \mathrm{~h}$ in vacuum to form $\mathrm{SiC}$ matrix. The as-synthesized C/SiC composites were denoted by CS0, CS1500, CS1800 and CS2400, respectively. 


\subsection{Test and Characterization}

The carbon yield of furfuryl was measured by thermogravimetry (TG). The test was carried out in argon from 25 to $1500{ }^{\circ} \mathrm{C}$ using a Netzsch STA-449F3 thermal analysis system with a heating rate of $10{ }^{\circ} \mathrm{C}$ /min. Mercury porosimetry (Auto Pore IV9510, Micromeritics Instrument Ltd, USA) was used to examine the pore size distribution of porous $\mathrm{C} / \mathrm{C}$ preforms. Bulk density and open porosity of the $\mathrm{C} / \mathrm{SiC}$ composites were obtained by Archimedes method.

Morphology and element distribution of the samples were characterized by scanning electron microcopy (SEM, Zeiss Supra 55, Germany), equipped with energy dispersive spectroscope (EDS). Crystalline structure and phase composition were investigated by X-ray diffraction (XRD, Rigaku D/MAX 2200 pc, Japan) using $\mathrm{Cu}_{\mathrm{a}}$ radiation.

Bending strength of the $\mathrm{C} / \mathrm{SiC}$ composites was measured using a three-point bending test (Instron 5565 , USA) with a span of $40 \mathrm{~mm}$. At least five samples with a dimension of $60 \mathrm{~mm} \times 9 \mathrm{~mm} \times 4 \mathrm{~mm}$ were used for the test. The loading rate was $0.5 \mathrm{~mm} / \mathrm{min}$ and the loading direction was perpendicular to the nonwoven layers.

\section{Results And Discussion}

\subsection{Effects of heat treatment on the porous $\mathrm{C} / \mathrm{C}$ preforms}

It is known that the morphology and structure of the porous $\mathrm{C} / \mathrm{C}$ preforms can be modified by appropriate heat treatment $[12,13]$. To investigate the effect of annealing on morphology of preforms, SEM images of porous $\mathrm{C} / \mathrm{C}$ preforms with and without heat treatment were shown in Fig. 2. It was shown that the untreated $\mathrm{C} / \mathrm{C}$ preform ( $\mathrm{CO}$ ) possessed a rather dense structure and the fiber web layer was rather smooth without many pores or particulates [Fig. 2(a-b)]. With the increase of annealing temperatures, the preforms showed an increasing pore volume and quantity [Fig. 2(c), (e) and (g)]. Meanwhile, small carbon particulates appeared on the surface of the fiber web layer [Fig. 2(d), (f) and (h)], which indicated a microstructure change of the fiber web layer.

Table 1

Pore characterization data of $\mathrm{C} / \mathrm{C}$ preforms 


\begin{tabular}{|c|c|c|c|c|}
\hline $\mathrm{C} / \mathrm{C}$ preforms & $\begin{array}{l}\text { Density } \\
/ \mathrm{g} \cdot \mathrm{cm}^{-3}\end{array}$ & Porosity/\% & Median pore size/ $\mu \mathrm{m}$ & Pore size concentration range/ $\mu \mathrm{m}$ \\
\hline $\mathrm{CO}$ & 144 & 859 & 61 & $2 \sim 10$ \\
\hline C1500 & 143 & 1365 & 93 & $2 \sim 20$ \\
\hline C1800 & 143 & 1283 & 86 & $2 \sim 20$ \\
\hline $\mathrm{C} 2400$ & 140 & 2338 & 117 & $7 \sim 40$ \\
\hline
\end{tabular}

The pore size distribution of the different $\mathrm{C} / \mathrm{C}$ preforms was obtained by the technique of mercury porosimetry and the results were shown in Fig. 3 and Table 1. It was indicated that after the heat treatment, the porosity of the $\mathrm{C} / \mathrm{C}$ preform was increased from $8.6-23.4 \%$ while the median pore size was increased from 6.1 to $11.7 \mu \mathrm{m}$. The sizes of most pores in $\mathrm{C} 0$ were between 1 and $10 \mu \mathrm{m}$, while the pore size distributions of $\mathrm{C} 1500$ and $\mathrm{C} 1800$ preforms were similar, ranging from 2 to $20 \mu \mathrm{m}$. However, the pore sizes showed a significant increase as the annealing temperature further increased. In $\mathrm{C} 2400,70 \%$ of the total pore volume was contributed from the pores with a size of $>10 \mu \mathrm{m}$. From Fig. 3 and Table 1, it can be suggested that the heat treatment for $1 \mathrm{~h}$ leaded to the higher porosity and a larger pore size of the $\mathrm{C} / \mathrm{C}$ preforms.

It is known that carbon matrix skeletons of $\mathrm{C} / \mathrm{C}$ preforms are formed by the pyrolysis of the furfuryl resin mixture. Based on the results in Fig. 3 and Table 1, it was inferred that the pore structure change of $\mathrm{C} / \mathrm{C}$ preforms during heat treatment might be attributed to the further pyrolysis from the remaining carbonized products of the furfuryl resin mixture. In order to confirm this assumption and investigate the detailed pyrolysis process of the furfuryl resin mixture during heat treatment, TG was tested from room temperature to $1500^{\circ} \mathrm{C}$ and the corresponding curve was presented in Fig. 4. A dramatic decline appeared between 150 and $500^{\circ} \mathrm{C}$, inferring the main pyrolysis process of the furfuryl resin mixture. In the present work, $\mathrm{C} / \mathrm{C}$ preforms were synthesized by pyrolysis of the furfuryl resin mixture at $900{ }^{\circ} \mathrm{C}$ for $1 \mathrm{~h}$. However, in Fig. 4, a trend of persisting declination could be observed up to $1500^{\circ} \mathrm{C}$. The result indicated that the furfuryl resin mixture and its carbonized products were still pyrolyzed at $1500{ }^{\circ} \mathrm{C}$ or even higher temperature, so the porosity and pore sizes of the $\mathrm{C} / \mathrm{C}$ preforms might further increase during heat treatment. Therefore, it is necessary to anneal the $\mathrm{C} / \mathrm{C}$ preforms to obtain an optimized pore structure.

Besides the porosity and pore size distribution, the carbon microstructure might be modified during heat treatment because of the graphitization of turbostratic carbon [14]. It is well known that the porous carbon pyrolyzed from resin shows a typical three-dimensional disordered network structure [15]. The disordered network structure could be changed into an ordered graphite structure during heating [16]. To identify the effect of heat treatment on the microstructure of the porous carbon matrix, XRD was used to examine its crystallinity and the result was shown in Fig. 5. With the increasing annealing temperature, 
the peak of $\mathrm{C}(002)$ became sharper and its full width at half maximum (FWHM) decreased gradually, which indicated the increased order degree of the carbon structure.

\subsection{Effects of different porous carbon structure on the RMI process}

The $\mathrm{C} / \mathrm{C}$ performs were annealed at different temperatures to modify their porous carbon structure, followed by being infiltrated with molten $\mathrm{Si}$ to fabricate the RMI C/SiC composites. According to the various annealing temperatures, the as-synthesized C/SiC samples were indicated as CS1500, CS1800 and CS2400, respectively. For comparison, the RMI C/SiC sample using the untreated C/C preform was also prepared (CSO).

Quantitative XRD tests were employed to investigate the phase composition and relative amount of $\mathrm{C} / \mathrm{SiC}$ composites. Corresponding results were exhibited in Fig. 6 . All the $\mathrm{C} / \mathrm{SiC}$ samples consisted of $\beta$-SiC, amorphous carbon and free Si peaks. The Si phase was from the unreacted residual Si during the infiltration. The intensity of $\mathrm{Si}$ and $\mathrm{SiC}$ peaks were used to determine their relative amounts (the relative amount of $\mathrm{C}$ could not be obtained because of its amorphism) and the results were listed in Table 2 . There were less residual Si (SiSiC < 0.1) in the CS0, CS1500 and CS1800, but significantly increased residual $\mathrm{Si}(\mathrm{SiSiC} \sim 0.5)$ could be detected in CS2400. The results indicated that the relatively large pore size of $\mathrm{C} 2400$ might cause the reaction of $\mathrm{Si}$ and $\mathrm{C}$ to be incomplete and then the melt Si to be left between the generated $\mathrm{SiC}$ phase. However the average pore size of $\mathrm{C} 0$ was so small that unreacted residual $\mathrm{C}$ might be remained after the reaction. Therefore, the $\mathrm{C} 1500$ and $\mathrm{C} 1800$ might be more suitable for RMI process.

Table 2

Porosity, density and matrix phase composition of $\mathrm{C} / \mathrm{SiC}$ composites

\begin{tabular}{|llll|}
\hline Samples & Porosity/\% & Density $/ \mathbf{g} \cdot \mathbf{c m}^{-3}$ & Relative amount ratio of SiC Si in matrix \\
\hline CS0 & 092 & 210 & 955 \\
\hline CS1500 & 089 & 199 & 8911 \\
\hline CS1800 & 093 & 214 & 964 \\
\hline CS2400 & 299 & 168 & 5248 \\
\hline
\end{tabular}

Figure 7 exhibited the cross-section SEM images of the C/SiC composites. The composites were composed of black, grey and light grey phases. Corresponding EDS analyses indicated that the black, grey and light grey phases were $\mathrm{C}, \mathrm{SiC}$ and $\mathrm{Si}$, respectively. The stacking structure of fiber web layers and non-woven layers were clear in the low-magnification SEM images [Fig. 7(a), (c), (e) and (g)] and the SiC and Si were mainly distributed in the fiber web layers because the non-woven layers were too compact for the infiltration of molten Si. Meanwhile, the micropores presented in the fiber web layers were beneficial for the Si infiltration via capillary force. It was worth noting that the volume ratio of the infiltrated Si in the 
composites increased when the annealing temperature was up to $2400^{\circ} \mathrm{C}$ [Fig. 7 (g)]. In addition, the detailed images confirmed that there were large amounts of residual Si and cracks in the CS2400 [Fig. 7(h)]. However, no obvious residual Si and cracks can be found in CS0, CS1500 and CS1800.

The above results indicates that the porous carbon structure of $\mathrm{C} / \mathrm{C}$ preforms could be modified by heat treatment, and further affects the fabrication of $\mathrm{C} / \mathrm{SiC}$ composites with different microstructure via $\mathrm{Si}$ infiltration. To illuminate the correlation between porous carbon structure and the microstructure of $\mathrm{C} / \mathrm{SiC}$ composites, it is essential to understand the effects of porous carbon structure on the RMI process. It is an exothermic reaction that occurred in the molten Si infiltration:

\section{$\mathrm{Si}(1)+\mathrm{C}(\mathrm{s}) \rightarrow \mathrm{SiC}(\mathrm{s})$}

The infiltration effect during RMI process is highly dependent on the pore sizes of $\mathrm{C} / \mathrm{C}$ preforms. On the one hand, smaller pores might lead to the incomplete infiltration of molten Si due to the "chock-off" phenomenon [Fig. 7(b)]. This phenomenon is attributed to the fact that, in the infiltration process, the diffusion channels of molten Si became narrower and even completely closed, and then the Si flow would stop. Meanwhile, for a preform with smaller pore sizes, the reaction rate between $\mathrm{Si}$ and $\mathrm{C}$ was faster than the infiltration rate of $\mathrm{Si}$, and the reaction was mild and limited. The reaction became nearly isothermal since the chemical reaction heat could be released outward in time. On the other hand, larger pores might result in the superfluous unreacted $\mathrm{Si}$ formed in the as-obtained $\mathrm{C} / \mathrm{SiC}$ composites due to the limitation of atom diffusion in reaction [Fig. 7(h)]. Besides, for a preform with larger pore sizes, the infiltration rate of $\mathrm{Si}$ was higher than the reaction rate between $\mathrm{Si}$ and $\mathrm{C}$. So molten Si would rapidly infiltrate and fill the pores of preforms. The reaction was violent and the reaction heat was hard to be released, which resulted in the rather high local temperature. Therefore, some microcracks would generate in the ceramic matrix because of the remarkable thermo-stress concentration [Fig. 7(h)] [17].

The porosity and density data of the porous $\mathrm{C} / \mathrm{C}$ preforms and $\mathrm{C} / \mathrm{SiC}$ composites were summarized in Table 1 and Table 2. It was shown that the porosity of $C / C$ preforms increased from $8.59-13.65 \%$ and $12.83 \%$ after annealing at $1500^{\circ} \mathrm{C}$ and $1800^{\circ} \mathrm{C}$, respectively. When the annealing temperature was raised to $2400{ }^{\circ} \mathrm{C}$, the porosity of $\mathrm{C} / \mathrm{C}$ preform was up to $23.38 \%$ (2.7 times higher than that before annealing). The increase of porosity could be ascribed to the further pyrolysis from the remaining carbonized product of the furfuryl resin mixture, which was confirmed in the TG test (Fig. 4). An appropriate porous C/C preform is the basis for the fabrication of $\mathrm{RMI} \mathrm{C/SiC} \mathrm{composites} \mathrm{with} \mathrm{optimized} \mathrm{microstructure.}$ Compared with CS0, CS1500 and CS1800, CS2400 had larger porosity and lower density. Given the fact that the density of $\mathrm{SiC}$ is higher than that of $\mathrm{Si}$ and $\mathrm{C}$, the result infers that in CS2400, less SiC could be generated and some large pores could not be filled completely due to the large pore size and porosity of C2400.

Besides the pore structure of carbon preforms, the effect of wettability and reactivity between $\mathrm{C}$ and $\mathrm{Si}$ ,which was attribute to the heat treatment, on the infiltration process is worth noting. 
The wettability of solid and liquid is highly related to their atomic or molecular structure [18]. Some previous researches indicated that the increasing structural order degree of carbon materials would result in the increasing wettability between liquid $\mathrm{Si}$ and solid carbon [19-21]. According to the Washburn model [22], the infiltration of liquid $\mathrm{Si}$ into porous $\mathrm{C}$ could be described by the following equation

$$
h \frac{d h}{d t}=\frac{R \sigma \cos \theta}{4 \eta}
$$

where,

$$
\frac{d h}{d t}
$$

is the infiltration rate, $h$ is the infiltration depth, $R$ is the capillary radius, $\eta$ is the viscosity, $\sigma$ is the surface tension, and $\theta$ is the equilibrium contact angle. Washburn equation indicates a negative correlation between equilibrium contact angle $\theta$ and infiltration speed/infiltration depth. Therefore, molten Si with a better wettability with carbon (a smaller contact angle $\theta$ ) will lead to an improved infiltration effect [23]. With the increasing structural order degree of carbon after annealing, the wettability was improved and the infiltration process was enhanced. In addition, the reactivity between the porous carbon substrate and the molten Si might be strengthened by heat treatment [24].

However, based on the results shown in Fig. 7 and Table 2, it can be inferred that, compared with the graphitization degree and reactivity of carbon matrix, the porous structure of carbon preforms is the main factor of the melt infiltration process. The $\mathrm{C} 1500$ and $\mathrm{C} 1800$ are more suitable for Si infiltration and forming dense $\mathrm{C} / \mathrm{SiC}$ composites without cracks.

\subsection{Mechanical properties of the $\mathrm{C} / \mathrm{SiC}$ composites with various porous carbon structure}

The results of mechanical properties of $\mathrm{C} / \mathrm{SiC}$ composites were given in Table 3 . It was obvious that the average bending strength and modulus of CS1500 and CS1800 were higher than those of CSO. As the annealing temperature of the $\mathrm{C} / \mathrm{C}$ preforms increased to $2400^{\circ} \mathrm{C}$, the strength and modulus of asobtained $\mathrm{C} / \mathrm{SiC}$ composites decreased. The bending strength of CS 2400 was $34 \%$ lower than that of CS1500.

The typical bending stress-strain curves for CS0, CS1500, CS1800 and CS2400 were shown in Fig. 8. It was obvious that CS1500 had the highest bending strength and toughness. All the four curves were composed of three stages (1) At first, the bending stress linearly increased with the bending strain, during which elastic deformation occurred. At this stage, no new cracks were formed in the matrix and the existing microcracks did not propagate. (2) When the bending strength reached a critical value, the curves 
were deviated from linearity to nonlinearity. The new cracks generated and the existing cracks began to grow. The increasing crack density with the rise of load resulted in the gradually declining stiffness of the composites till the first bundle of fibers broke and the curves reached maximum stress. (3) After the peak stress, the curves fell slowly in a step-like mode instead of catastrophic failure, indicating a typical pseudo-plastic fracture behavior.

Table 3

Bending mechanical properties of as-prepared $\mathrm{C} / \mathrm{SiC}$ composites

\begin{tabular}{|lll|}
\hline Samples & Strength/MPa & Modulus/GPa \\
\hline CS0 & $214 \pm 53$ & $20 \pm 5$ \\
CS1500 & $276 \pm 24$ & $27 \pm 2$ \\
CS1800 & $242 \pm 33$ & $24 \pm 4$ \\
CS2400 & $172 \pm 23$ & $17 \pm 2$ \\
\hline
\end{tabular}

Figure 9 presented the typical macroscopic and microscopic fracture morphology of the $\mathrm{C} / \mathrm{SiC}$ composites after three-point bending tests. The average pull-out length of the fibers in CS1500 was about $5 \mathrm{~mm}$ and the delamination between different layers can be observed [Fig. 9 (b)]. In CS1800, the fiber pullout length was shorter than that of CS1500 and no obvious delamination can be found [Fig. 9(c)]. While compared with CS1500 and CS1800, CS2400 showed a much shorter pull-out length ( $2 \mathrm{~mm}$ ) without delamination [Fig. 9(d)]. The fiber pull-out length of CSO $(\sim 2.5 \mathrm{~mm})$ was a little longer than that of CS2400 [Fig. 9(d)].

During the loading process, the stress would be transferred from the matrix to the fibers by the interface. The cracks in matrix would be deflected when they encountered the weak PyC interface and then propagated along the direction paralleled to the fiber axis [25]. When the stress exceeded the in-situ strength of a fiber and the interface was weak enough, the fiber would be fractured and pulled out, resulting in the increasing fracture energy and the improved bending strength and toughness. According to Fig. 9, in comparison with other composites (CS0, CS1800 and CS2400), the longer pull-out length of fibers and the obvious delamination can be observed in CS1500, suggesting a better toughness. The result was in consistent with the stress-train curves in Fig. 8.

From results above, it can be indicated that after appropriate heat treatment for the $\mathrm{C} / \mathrm{C}$ preforms, the porous carbon structure was optimized and the strength of the as-synthesized $\mathrm{C} / \mathrm{SiC}$ composites increased (CS1500 and CS1800). But the excessive annealing temperature for C/C preforms will lead to a decreased strength of the C/SiC composites (CS2400). Generally, the mechanical properties of composites can be influenced by various factors, such as density, matrix microstructure, bonding strength of interface, fiber properties, and preform architecture [26]. In the present work, when the annealing temperature was up to $2400{ }^{\circ} \mathrm{C}$, the pore size and porosity of $\mathrm{C} / \mathrm{C}$ preforms increased significantly. Higher 
local thermal stress was generated in the as-synthesized $\mathrm{C} / \mathrm{SiC}$ composites owing to the release of massive reaction heat during RMI process. In addition, the porosity of CS2400 was quite higher than that of other composites and the pores might be the crack initiation. Hence, the existing cracks and high porosity of CS2400 were detrimental for its mechanical properties. Meanwhile, as the main load-carrying component, the continuous carbon fibers with a volume fraction of $40 \%$ played an important role in the mechanical properties of $\mathrm{C} / \mathrm{SiC}$ composites. Excessive annealing temperature might result in the degraded fiber in-situ strength [27].

To clarify the effect of heat treatment on the in-situ strengths of carbon fibers, the fiber fracture surfaces of the different $\mathrm{C} / \mathrm{SiC}$ composites after bending test were inspected by SEM to compare their in-situ strengths (Fig. 10). The in-situ strength of fiber can be calculated using the following equation [28]

$$
S=\frac{A_{m}}{\sqrt{r_{m}}}
$$

where $S$ is the in-situ fiber strength, $A_{m}$ is a constant related to fiber type, and $r_{m}$ is the mirror radius of the fractured fiber.

In general, the cross-section of a fractured fiber consists of four parts source, mirror, mist, hackle [29]. The outer mirror radius $\left(r_{m}\right)$ is the distance from the origin to the onset of hackle. However, the morphology of fracture surface in the CSO and CS1500 were rather rough that the measurement of mirror radius was difficult [Fig. 10(a-b)]. This phenomenon infers that the in-situ fiber strength of CS0 and CS1500 were quite high. The fracture surface of fibers in CS1800 and CS2400 showed clearer mirror radiuses, which were about $1 \mu \mathrm{m}$ and $1.54 \mu \mathrm{m}$, respectively [Fig. 10(c-d)]. The larger mirror radius suggested the degradation of in-situ fiber strength in CS2400 [28]. Overall, the strength of RMI C/SiC composites was determined by the combined effects of the porosity, the existing cracks and the in-situ strength of fibers.

\section{Conclusions}

$\mathrm{RMI} \mathrm{C/SiC} \mathrm{composites} \mathrm{with} \mathrm{enhanced} \mathrm{mechanical} \mathrm{property} \mathrm{were} \mathrm{prepared} \mathrm{by} \mathrm{optimizing} \mathrm{the} \mathrm{porous}$ carbon structure using a simple method of heat treatment. The effects of heat treatment on the structure of porous carbon preforms, RMI process and mechanical properties of $\mathrm{C} / \mathrm{SiC}$ composites were investigated in detail. The porosity and average pore size of the porous carbon preforms increased as the heat treatment temperature increased. The optimal pore structure of porous carbon preforms could be obtained after heat treatment at $1500{ }^{\circ} \mathrm{C}$, which is beneficial to infiltrate molten Si. The microstructure of $\mathrm{C} / \mathrm{SiC}$ composites with optimal pore structure are dense and nearly without cracks. Therefore, owing to the lower porosity, the good in-situ strength of fibers and the less matrix cracks, the as-prepared $\mathrm{C} / \mathrm{SiC}$ composites present a superior mechanical property and a pseudo-plastic fracture behavior. The pull-out of fibers and the delamination of composites could be observed during the fracture of samples. 


\section{Declarations}

\section{Acknowledgements}

This work was financially supported by the National Natural Science Foundation of China (51902010) and Beijing Municipal Science and Technology Project (Z171100005317001).

\section{References}

1. Gleeson B (2012) Thermal barrier coatings for aeroengine applications. J Propul Power 22:375-383

2. Liu GW, Zhang XZ, Yang J et al (2019) Recent advances in joining of SiC-based materials (monolithic $\mathrm{SiC}$ and $\mathrm{SiC}_{f} / \mathrm{SiC}$ composites): Joining processes, joint strength, and interfacial behavior. J Adv Ceram 8:19-38

3. Wu D, Wang Y, Lan S, Ying P, Gao Z (2016) Thermo-mechanical properties of C/SiC composite structure under extremely high temperature environment up to $1500{ }^{\circ} \mathrm{C}$. Compos B Eng 90:424-431

4. Kumar P, Srivastava VK (2016) Tribological behaviour of C/C-SiC composites-A review. J Adv Ceram $5: 1-12$

5. Corman GS, Luthra KL (2005) Silicon melt infiltrated ceramic composites (HiPerComp ${ }^{\mathrm{TM}}$ ). In: Bansal NP (ed) Handbook of ceramic composites. Springer, Boston, pp 99-115

6. Tang SF, Hu CL (2017) Design, preparation and properties of carbon fiber reinforced ultra-high temperature ceramic composites for aerospace applications-A Review. J Mater Sci Technol 33:117130

7. Zhong Q, Zhang XY, Dong SM et al (2017) Reactive melt infiltrated $C_{f} / S i C$ composites with robust matrix derived from novel engineered pyrolytic carbon structure. Ceram Int 43:5832-5836

8. Tong YG, Cai ZH, Bai SX et al (2018) Microstructures and properties of Si-Zr alloy based CMCs reinforced by various porous C/C performs. Ceram Int 44:16577-16582

9. Wang YX, Tan SH, Jiang DL (2004) The effect of porous carbon preform and the infiltration process on the properties of reaction-formed SiC. Carbon 42:1833-1839

10. Margiotta JC, Zhang D, Nagle DC et al (2008) Formation of dense silicon carbide by liquid silicon infiltration of carbon with engineered structure. J Mater Res 23:1237-1248

11. Singh M, Behrendt DR (1994) Reactive melt infiltration of silicon-niobium alloys in microporous carbons. J Mater Res 9:1701-1708

12. Wang $Y X$, Tan SH, Jiang DL et al (2003) Preparation of porous carbon derived from mixtures of furfuryl resin and glycol with controlled pore size distribution. Carbon 41:2065-2072

13. Rodriguez-Reinoso F, Marsh H, Heintz EA (1997) Introduction in Carbon Technology. Universidad de Alicante Press, Alicante

14. Oberlin A (1984) Carbonization and graphitization. Carbon 22:521-541 
15. Kobayashi K, Sugawara S, Toyoda S et al (1968) An X-ray diffraction study of phenol-formaldehyde resin carbons. Carbon 6:359-363

16. Tanaka H, Kaburagi Y, Kimura S (1978) Graphitization behaviour of carbon fibre-glassy carbon composites. J Mater Sci 13:2555-2559

17. Singh M, Behrendt DR (1992) Studies on the reactive melt infiltration of silicon and siliconmolybdenum alloys in porous carbon. J Surg Res 105:1361-1344

18. Eustathopoulos N, Nicholas MG, Drevet B (1999) Wettability at high temperatures. Elsevier Press, Oxford

19. Dezellus $O$, Jacques $S$, Hodaj $F$ et al (2005) Wetting and infiltration of carbon by liquid silicon. J Mater Sci 40:2307-2311

20. Whalen TJ, Anderson AT (2010) Wetting of $\mathrm{SiC}, \mathrm{Si}_{3} \mathrm{~N}_{4}$, and Carbon by Si and Binary Si Alloys. J Am Ceram Soc 58:396-399

21. Li JG, Hausner H (2010) Reactive Wetting in the liquid-silicon/solid-carbon system. J Am Ceram Soc 79:873-880

22. Washburn EW (1921) The dynamics of capillary flow. Phys rev ser 17:273-283

23. Tong Y, Bai S, Liang $X$ et al (2016) Reactive melt infiltration fabrication of C/C-SiC composite Wetting and infiltration. Ceram Int 42:17174-17178

24. Calderon NR, Martínez-Escandell M, Narciso J (2009) The combined effect of porosity and reactivity of the carbon preforms on the properties of $\mathrm{SiC}$ produced by reactive infiltration with liquid $\mathrm{Si}$. Carbon 47:2200-2210

25. Yang LW, Liu HT, Cheng HF (2017) Processing-temperature dependent micro- and macro-mechanical properties of SiC fiber reinforced SiC matrix composites. Compos B Eng 129:152-161

26. Pujar VV, Cawley JD (2010) Effect of Stacking Faults on the X-Ray Diffraction Profiles of 3C-SiC Powder. J Am Ceram Soc 78:774-782

27. Hatta H (2004) Tensile Strength of Carbon-Carbon Composites II-Effect, of Heat Treatment Temperature. J Compos Mater 38:1685-1699

28. Davies IJ, Ishikawa T, Shibuya M (1999) Fibre strength parameters measured in situ for ceramicmatrix composites tested at elevated temperature in vacuum and in air. Compos Sci Technol 59:801-811

29. Mecholsky JJ, Rice RW, Freiman SW (2006) Prediction of fracture energy and flaw size in glasses from measurements of mirror size. J Am Ceram Soc 57:440-443

\section{Figures}




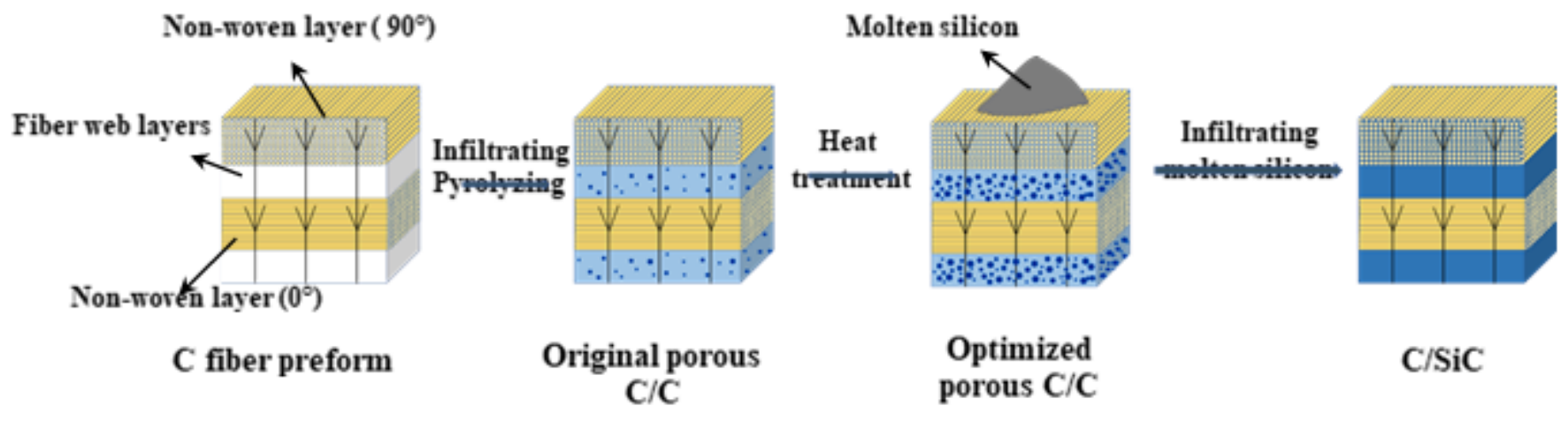

Figure 1

Schematic for the preparation of RMI C/SiC composites 

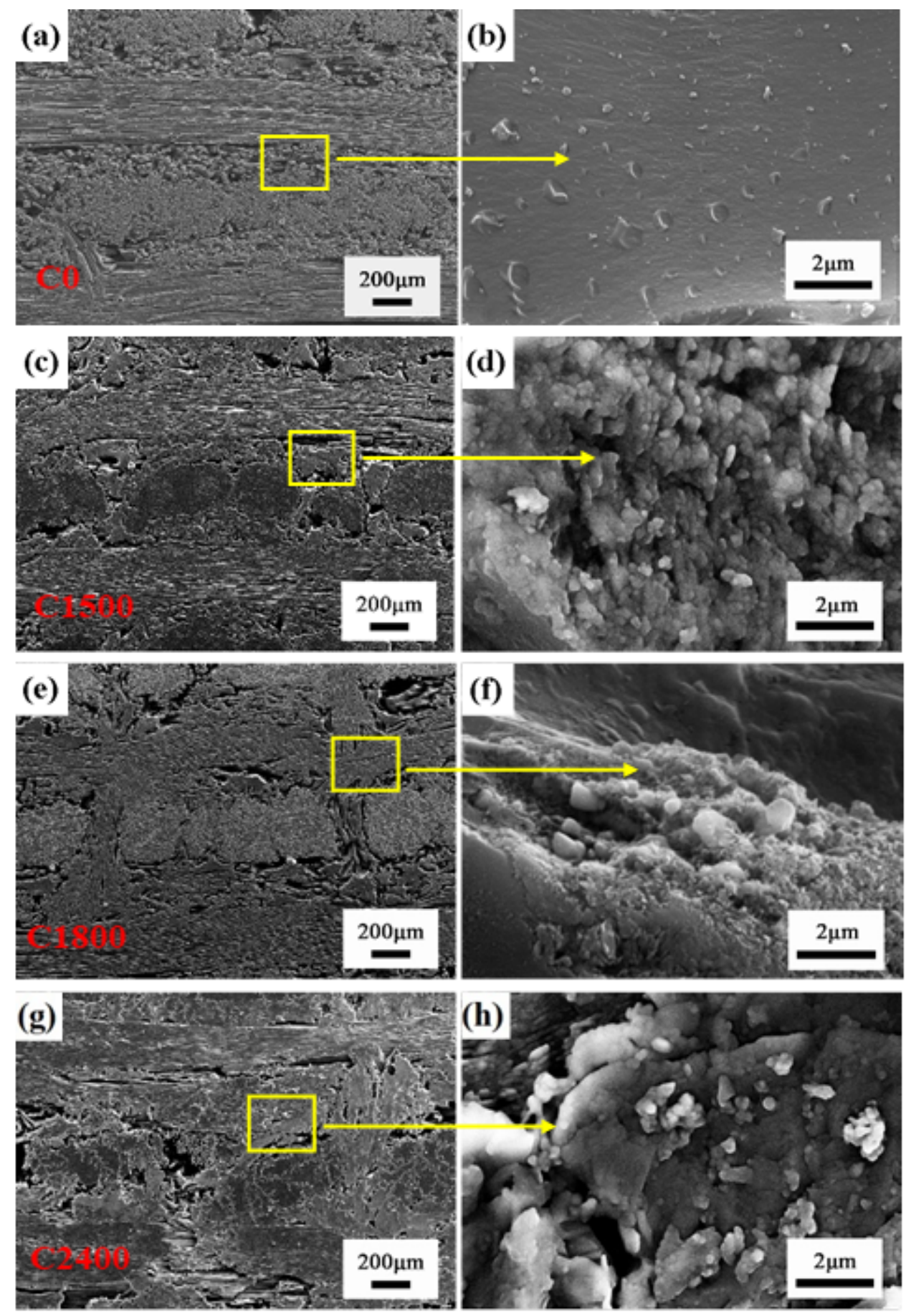

Figure 2

SEM images of the C/C preforms with and without heat treatment (a), (c), (e) and (g) C0, C1500, C1800 and C2400 at low magnification; (b), (d), (f) and (h) C0, C1500, C1800 and C2400 at high magnification; (b), (d), (f) and (h) are all images of fiber web layers 


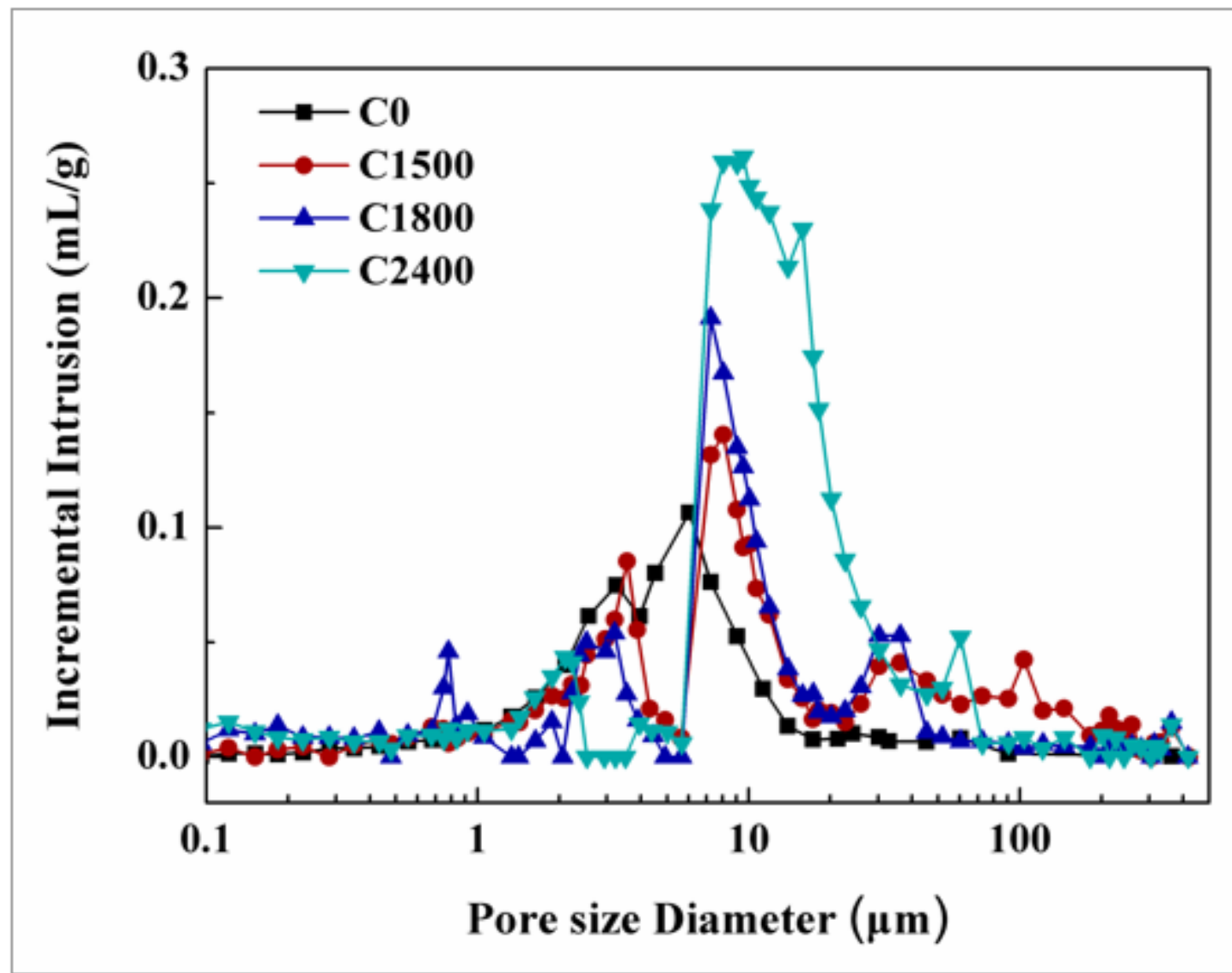

Figure 3

Typical pore size distribution of $\mathrm{C} / \mathrm{C}$ preforms before and after heat treatment 


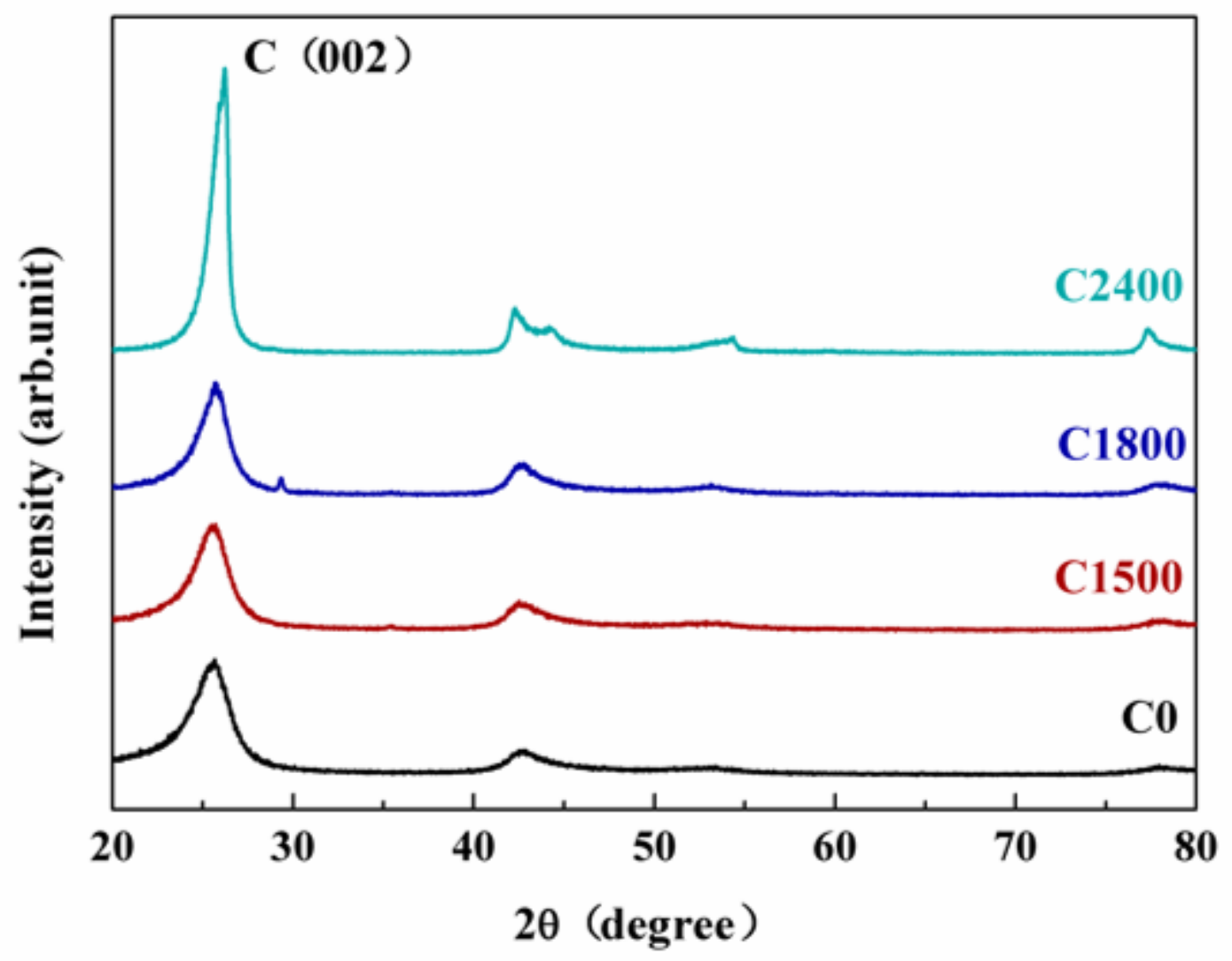

Figure 4

TG curve of furfuryl resin mixture 


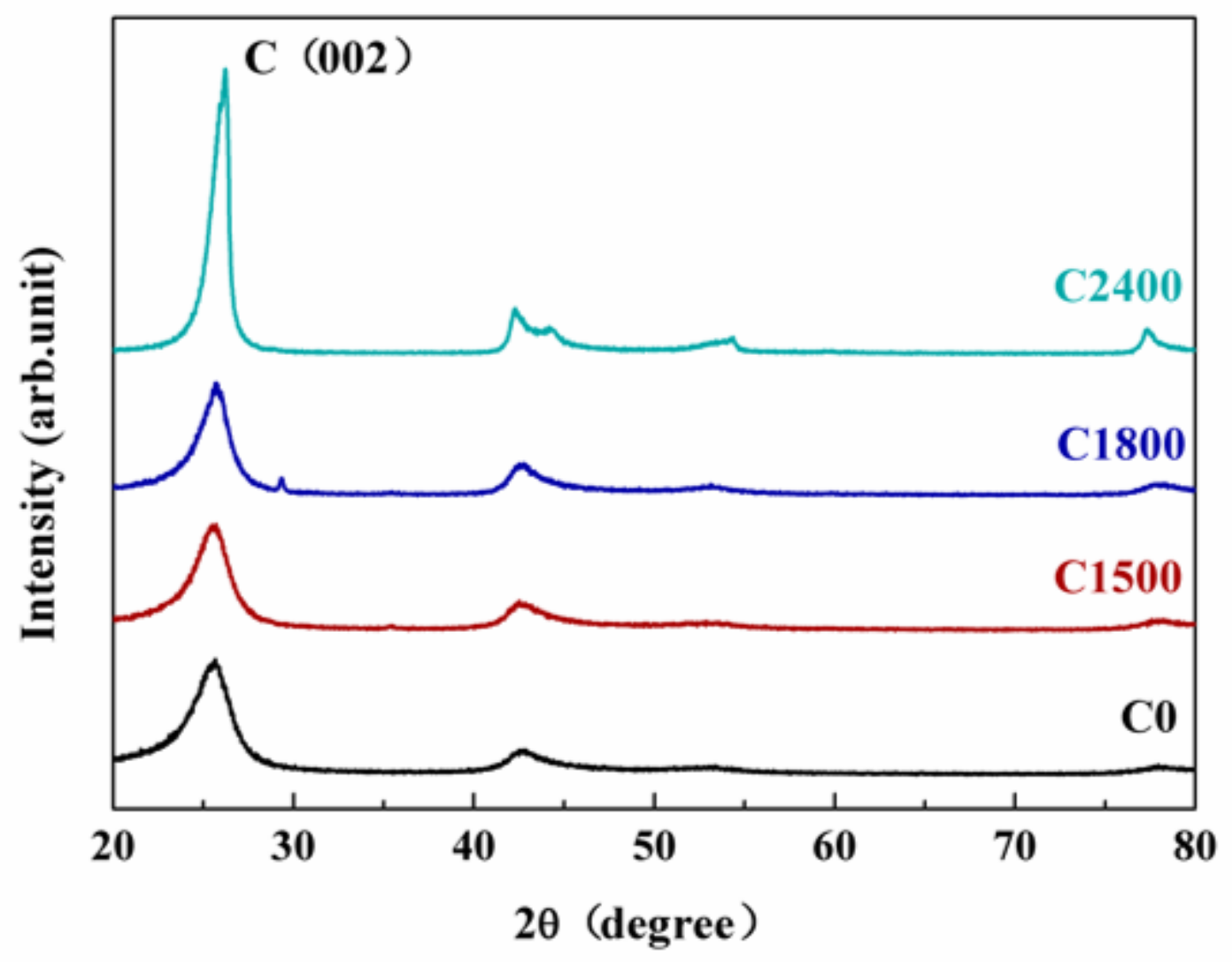

Figure 5

XRD patterns of $\mathrm{C} / \mathrm{C}$ preforms with and without heat treatment 


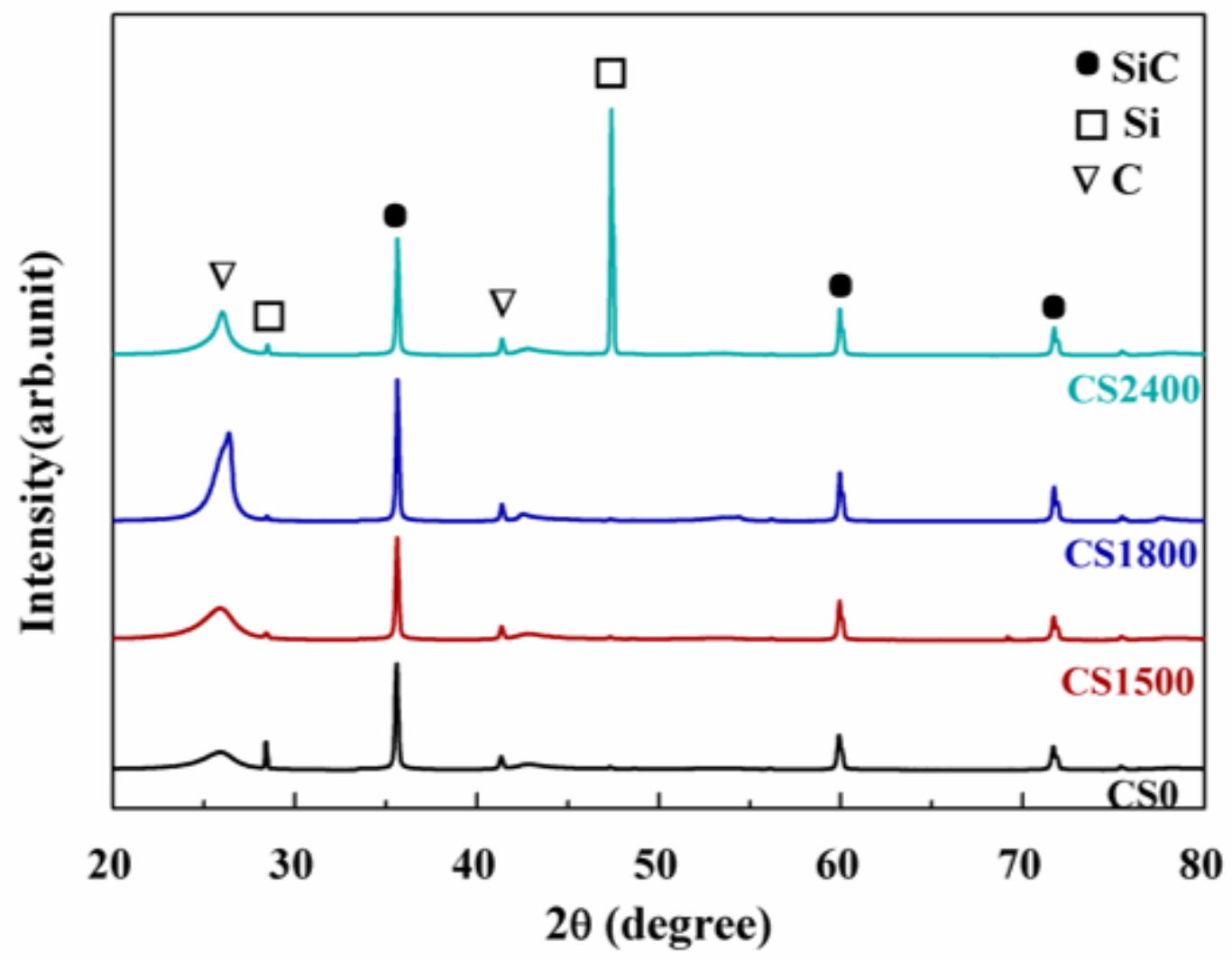

Figure 6

XRD patterns of $\mathrm{C} / \mathrm{SiC}$ composites 

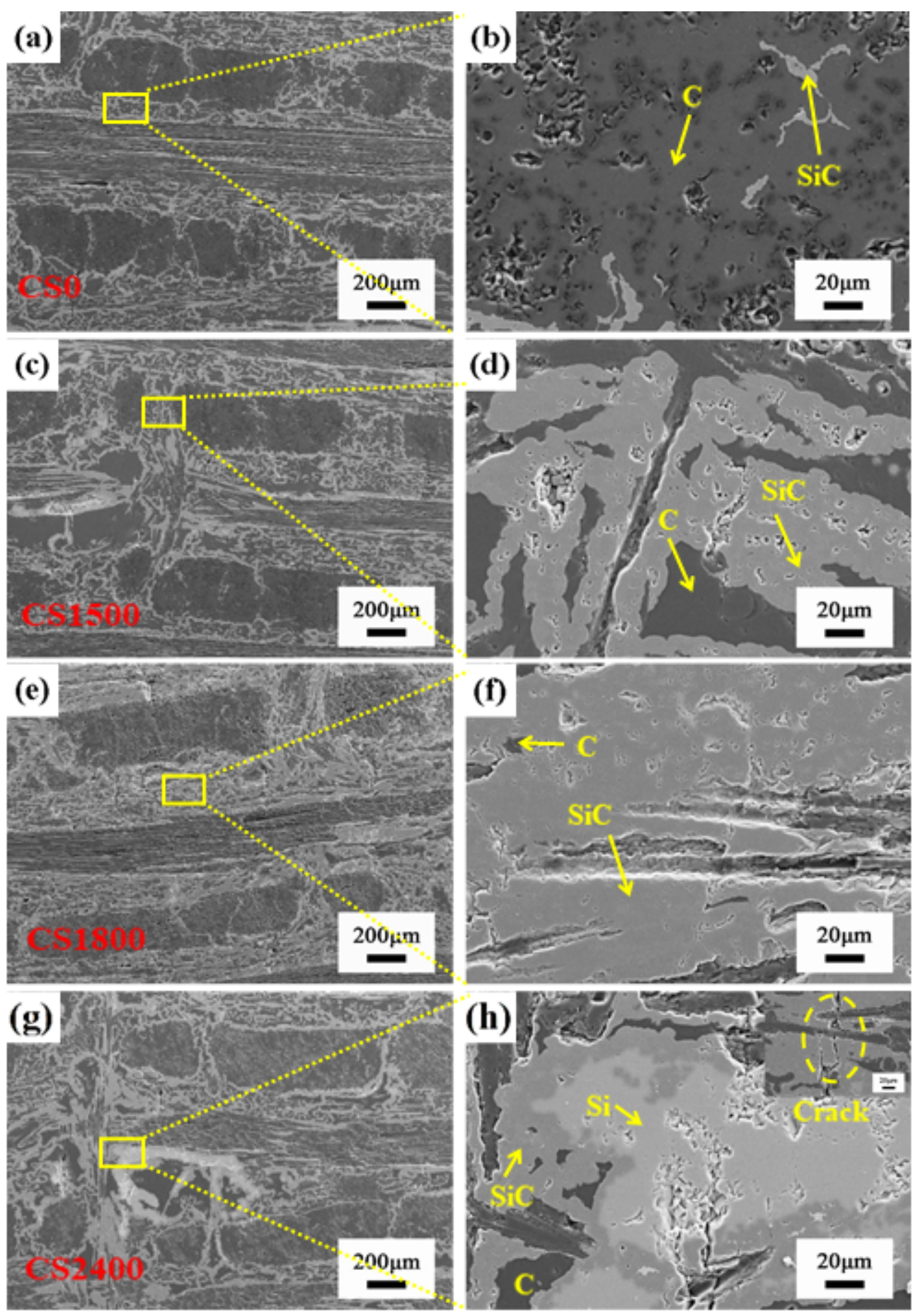

Figure 7

SEM micrographs of the cross sections of C/SiC composites (a) and (b) CSO, (c) and (d) CS1500, (e) and (f) CS1800, (g) and (h) CS2400 


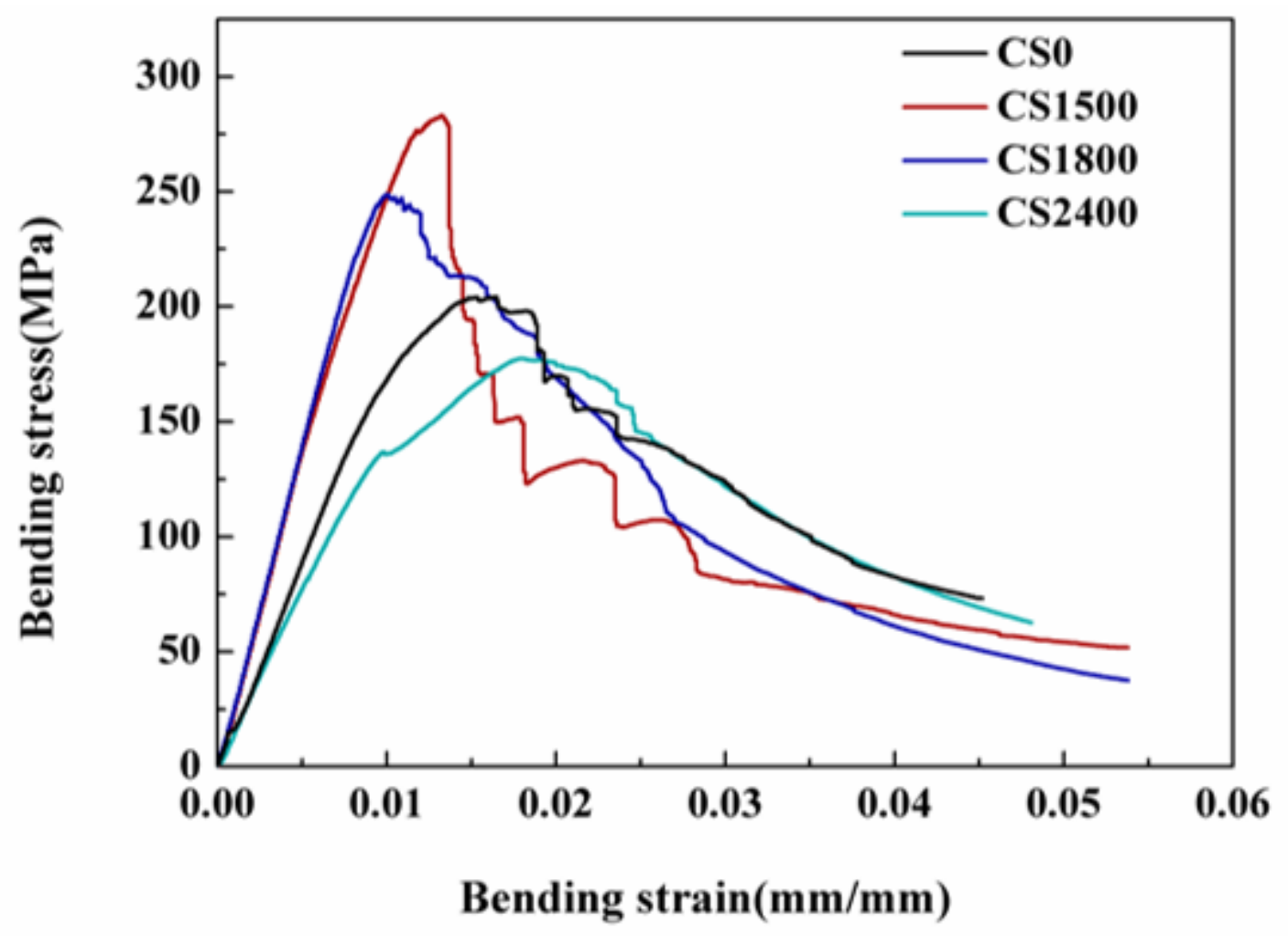

Figure 8

Typical bending stress-train curves of CS0, CS1500, CS1800 and CS2400 


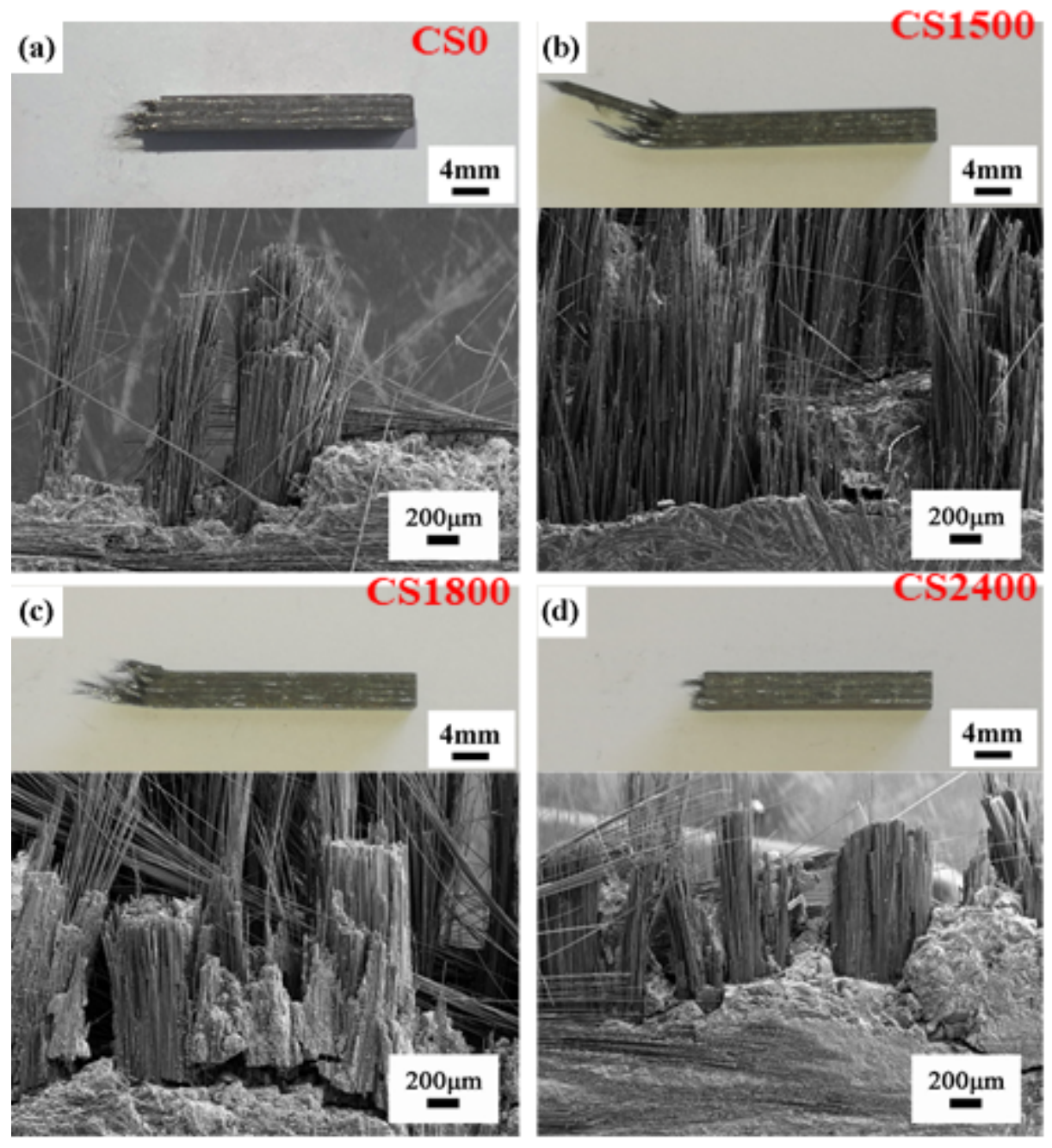

Figure 9

Macroscopic and SEM images of fracture morphology of C/SiC composites (a) CS0, (b) CS1500, (c) CS1800, (d) CS2400 

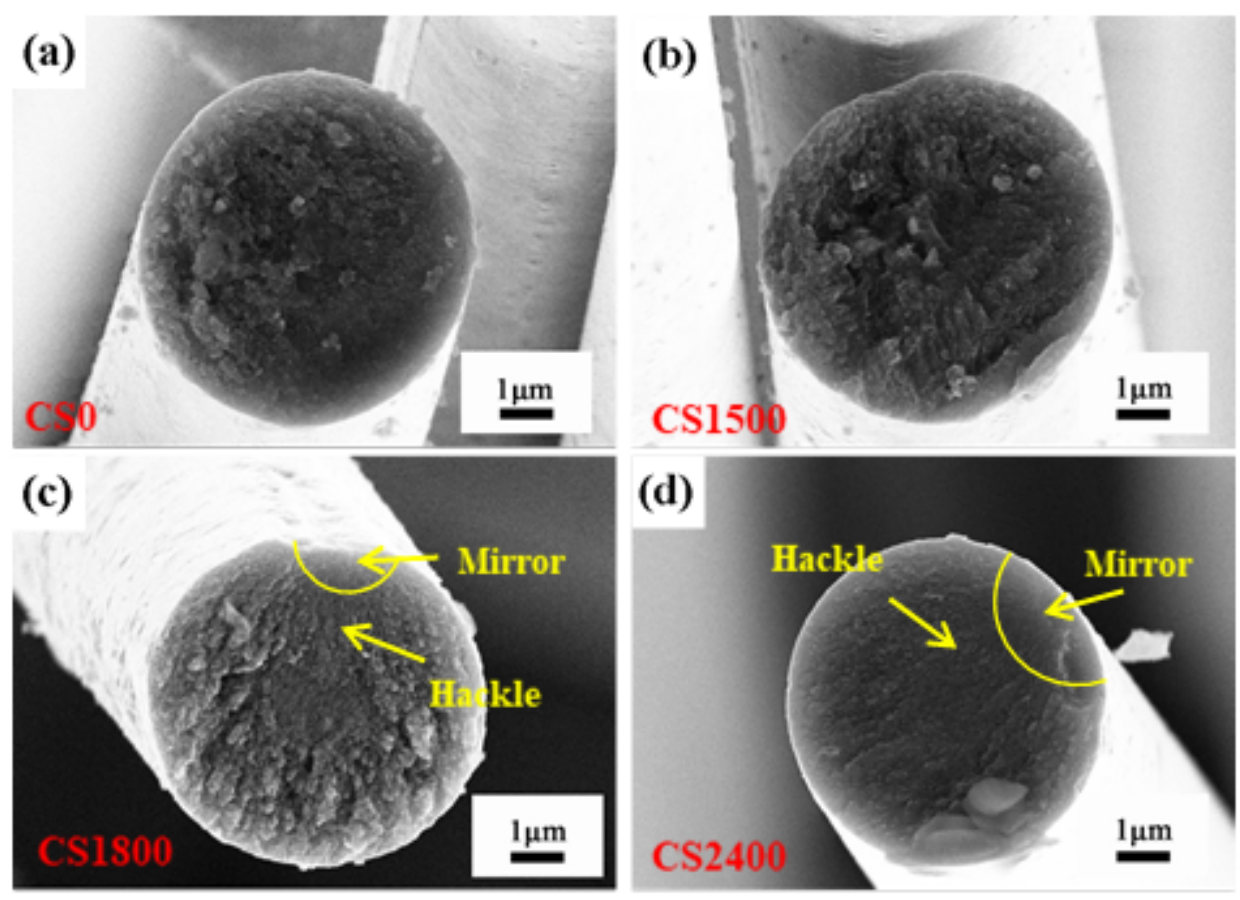

Figure 10

Fracture morphology of fibers in $\mathrm{C} / \mathrm{SiC}$ composites 